\title{
Aprendizagem profissional: trabalho e desenvolvimento social e econômico
}

\author{
ANA LUCIA DE ALENCASTRO GONÇALVES ${ }^{I}$
}

\section{O que é a aprendizagem profissional}

A

LEI DA aprendizagem profissional garante um contrato formal de trabalho, de até dois anos, a adolescentes e jovens com idade entre 14 e 24 anos, com a principal finalidade de propiciar a esse segmento da juventude o acesso à “formação técnico-profissional metódica”, organizada em um programa previamente aprovado pela Secretaria de Políticas Públicas de Emprego e sujeito à fiscalização da Inspeção do Trabalho.

Obrigação prevista no art. 429 da CLT para todos os estabelecimentos de médio e grande portes que devem cumprir cotas, a contratação de aprendizes é facultada a micro e pequenas empresas, e também vem sendo ampliada em alguns órgãos da administração direta com base nas mesmas premissas legais.

O princípio em que se sustenta a aprendizagem, um contrato de trabalho em que o "aspecto formativo deve se sobrepor ao produtivo", como configurado no art. 429 da CLT, envolve outro ente, não presente nas relações comuns de trabalho, que é a entidade formadora habilitada.

Art. 429 - Os estabelecimentos de qualquer natureza são obrigados a empregar e matricular nos cursos dos Serviços Nacionais de Aprendizagem número de aprendizes equivalente a 5\%, no mínimo, e 15\%, no máximo, dos trabalhadores existentes em cada estabelecimento, cujas funções demandem formação profissional.

A grande maioria das empresas de grande e médio portes irá efetuar as matrículas em programas ofertados por esses Serviços, conhecidos como Sistema S, com o qual contribuem a depender da natureza de suas atividades na indústria, nos comércio e serviços, transporte, agricultura ou cooperativas. Caso a empresa não realize a contribuição compulsória a nenhum desses serviços, ou sua unidade local não tenha disponibilidade de matrículas para ofertar, esse empregador deve procurar as demais entidades autorizadas, como a Rede de Escolas Federais, Estaduais e Municipais ou as entidades sem fins lucrativos.

O Programa de Aprendizagem Profissional, cuja duração se define por igual período do contrato, deve prever a alternância de aulas teóricas e atividades práticas referentes à ocupação/profissão objeto da formação daquele beneficiá- 
rio, vivenciadas nas entidades formadoras habilitadas e nas empresas contratantes, respectivamente.

A jornada de trabalho do aprendiz deverá ser de no máximo seis horas diárias, podendo se estender até oito horas diárias para os aprendizes que já tenham concluído o Ensino Fundamental, se nelas forem computadas as horas destinadas à aprendizagem teórica. São vedadas a prorrogação e a compensação de jornada.

Ao aprendiz, salvo condição mais favorável fixada no contrato de aprendizagem (por liberalidade do empregador ou prevista em convenção ou acordo coletivo de trabalho, onde se especifique o salário mais favorável ao aprendiz, bem como o piso regional), será garantido o salário mínimo hora, o direito ao benefício do vale transporte para frequentar tanto as atividades teóricas quanto as jornadas destinadas a prática profissional da(s) ocupação(s), explicitadas no programa técnico-pedagógico. O depósito devido ao Fundo de Garantia por Tempo de Serviço (FGTS) corresponderá a $2 \%$ da remuneração paga ou devida, no mês anterior, ao empregado aprendiz. E ficam assegurados ao aprendiz os demais direitos trabalhistas e previdenciários compatíveis com o contrato de aprendizagem.

As férias do empregado aprendiz deverão coincidir com um dos períodos das férias escolares do ensino regular quando solicitado, em conformidade com o $\$ 2^{\circ}$ do art. 136 da CLT, sendo vedado o parcelamento, nos termos do $\$ 2^{\circ}$ do art. 134 da CLT.

$\mathrm{O}$ contrato de aprendizagem extinguir-se-á no seu termo ou quando o aprendiz completar 24 anos, ressalvada a hipótese prevista no $\$ 5^{\circ}$ do art. 428 da CLT, ou, ainda antecipadamente, nas seguintes hipóteses:

- desempenho insuficiente ou inadaptação do aprendiz;

- falta disciplinar grave (previstas no art. 482 da CLT);

- ausência injustificada à escola que implique perda do ano letivo, caracterizada por meio de declaração da instituição de ensino; ou

- a pedido do aprendiz.

Nas hipóteses de extinção do contrato mencionadas aqui, não se aplicam as indenizações referentes aos contratos por tempo determinado, previstas nos art. 479 e 480 da CLT.

$\mathrm{Na}$ extinção total da empresa, fechamento de estabelecimento ou falecimento do empregador individual dar-se-á a rescisão antecipada do contrato de aprendizagem sem justa causa, com a incidência da indenização prevista no art. 479 da CLT, quando for o caso. É facultado ao aprendiz prosseguir no Curso ou Programa de Aprendizagem mediante contrato específico com outro estabelecimento.

O direito de todos os jovens a oportunidades de trabalho decente

O trabalho segue sendo uma das maiores preocupações na vida de jovens em qualquer estratificação social. No entanto, o artigo pretende voltar o olhar 
para o segmento mais vulnerável dessa população; àqueles para os quais a dita sociedade do conhecimento ou a expressão capital intelectual empregados no âmbito de universidades e grandes empresas desde o século passado, despertando interesses e investimentos da família, dos governos e das instituições envolvidas direta ou indiretamente com o binômio trabalho \& educação, não impacta absolutamente a "escolha" por uma colocação no mercado de trabalho. Esse grupo vai ser inserido em atividades precárias, a grande maioria na informalidade, sem nenhuma proteção e expectativa de futuro. Estamos falando do grande contingente da população jovem a quem resta pressionar sua rede de contatos quando entendem ter chegado a hora de buscar uma colocação no mercado. Motivados pela necessidade de obter renda para subsistência própria e/ou da família, ou acesso aos bens impostos a todos pela sociedade do consumo, ou pela descrença nos estudos como propulsor de melhores condições de vida no futuro, considerando o agravante que muitas vezes a escola é mais entediante do que motivadora e criativa, não lhes é garantida a oportunidade ao trabalho decente, conceito explorado no documento Agenda Nacional de Trabalho Decente para a Juventude - ANTDJ ${ }^{1}$ que pode ser resumido em quatro pontos principais:

- Mais e Melhor Educação

- Conciliação de Estudos, Trabalho e Vida Familiar

- Inserção Ativa e Digna no Mundo do Trabalho

- Diálogo Social.

$\mathrm{Na}$ realidade, esses pontos deveriam nortear toda a oferta de oportunidades de trabalho para adolescentes e jovens, em especial por ocasião de suas primeiras experiências, sem o que praticamente não existem reais perspectivas de crescimento ou de boas trajetórias; seja a inclusão no mundo laboral realizada por vagas de estágio, trainee ou em outras ações empreendedoras, a condição especial desse momento da vida merece um olhar especial da sociedade e do mercado de trabalho. Aqui queremos discorrer brevemente sobre como cada um desses itens pode se concretizar sob a égide de contratos de aprendizagem.

\section{Mais e Melhor Educação}

O aprendiz deve estar matriculado em instituição oficial de ensino, salvo se já houver concluído o Ensino Médio; em paralelo, é condição fundamental para aumentar as oportunidades de acesso a um trabalho de mais qualidade e mais protegido. No entanto, de acordo com o Ipea, 23\% da PEA juvenil (16 a 29 anos) não completaram nem o Ensino Fundamental. Em publicação do IBGE 2013, em 2012, 20\% dos jovens entre 15 e 29 anos não estavam estudando nem trabalhando.

O contrato de aprendizagem é, sem dúvida, uma forma de retenção na escola ou de volta aos estudos, mesmo que seja pela modalidade de Educação de Jovens e Adultos (EJA) para os que demonstram defasagem em razão da idade. 
Se forem proporcionados aos estudantes contratos de trabalho de aprendizagem, o que pode ocorrer a partir dos 14 anos para os interessados, evita-se a evasão precoce e muitas vezes irreversível, promovendo as condições para uma transição entre a escola e o mundo do trabalho, iniciando um itinerário formativo desde o contato com os processos produtivos das organizações empresariais.

Podemos, portanto, dizer que o instituto legal contribui para a progressão da escolaridade formal e o direito à formação profissional, visto que desenvolvido a partir de um programa técnico pedagógico concebido com base nas diretrizes nacionais da Educação Profissional e Tecnológica e ainda incluem o acesso às tecnologias de informação e comunicação, os conhecimentos relacionados à segurança e saúde no trabalho, para além das habilidades específicas de uma ou mais ocupações.

\section{Conciliação de Estudos, Trabalho e Vida Familiar}

As jornadas devem respeitar o tempo necessário aos estudos regulares $\mathrm{e}$ de atividades esportivas e culturais; normalmente são jornadas de quatro horas diárias para adolescentes, de seis horas para jovens, podendo ser de oito horas se for possível conciliar teoria e prática no mesmo dia.

Devem ser as férias coincidentes com os períodos escolares para adolescentes - para jovens, preferencialmente. As empresas que disponibilizam creches facilitam a inserção de jovens mães.

Em áreas rurais as jornadas podem ser diferenciadas, bem como no caso de o empregador, seja público ou privado, preferir focalizar sua contratação em segmentos mais vulneráveis como os egressos de medidas socioeducativas ou adolescentes residentes em abrigos.

\section{Inserção Ativa e Digna no Mundo do Trabalbo}

Trata-se de Inserção protegida e qualificada via emprego formal, com Carteira de Trabalho (CTPS) assinada e Direitos trabalhistas e previdenciários promovendo uma solução a mais para a erradicação do trabalho infantil e para o combate à precarização e ao grande índice de rotatividade de determinados segmentos do mercado.

Os contratos podem ser adotados para formação de mão de obra em nível de formação inicial ou em nível técnico de ensino, atingindo todos os setores da economia, inclusive sob programas direcionados a formar futuros empreendedores.

Para beneficiar Pessoas com Deficiência que recebem o Benefício de Prestação Continuada (BPC), direito garantido aos desempregados em razão de outras vulnerabilidades de caráter socioeconômico, a lei permite que esse benefício seja mantido durante a vigência do contrato de aprendizagem. Sem dúvida um estímulo para que essas pessoas possam investir no domínio de uma profissão, para que depois possam proclamar sua autonomia financeira.

\section{Diálogo Social}

Os espaços de debate em torno do instituto da aprendizagem ainda estão em fase de consolidação, mas o interesse crescente de instituições, órgãos e 
empresas em participar do Fórum Nacional (FNAP) pode apressar esse fortalecimento.

Instituído ao final de 2008, visando à mobilização de empregadores, governantes, sindicatos de classe, o Fórum tem se desdobrado em instâncias estaduais e motivado a articulação da lei do aprendiz com políticas locais e setoriais de desenvolvimento social e econômico.

Em alguns estados vê-se a participação ativa de aprendizes e egressos, demonstrando o significado da formação para o surgimento de profissionais criativos, inquietos e com capacidade crítica para oxigenar e impactar a competitividade das organizações que investem em capital humano.

Curiosamente, os representantes de empregados não parecem ter despertado para o significado e alcance da lei em favor dos futuros trabalhadores; deveriam ser esses os maiores preocupados em estimular aprendizes nos processos de negociações e tornar o aprendiz contemplado em convenções coletivas.

Sem sombra de dúvida será o diálogo social a mola propulsora de uma ação coletiva de governos, empregadores e representantes de empregados para a expansão significativa dessas oportunidades para adolescentes, jovens e pessoas com deficiência. E isso serve para qualquer contexto social e econômico, posto que sempre existirão pessoas sob essas condições que precisam de uma primeira oportunidade digna.

\section{Aprendizagem para inclusão de Pessoas com Deficiência}

Distintas em seus objetivos, as leis de cotas para pessoas com deficiência e da aprendizagem podem tornar-se complementares, em situação prevista legalmente para que o limite máximo de 24 anos estipulado pela Lei n.10.097 de 2000 seja rompido quando se tratar da contratação de pessoa com deficiência que necessite de formação profissional para o exercício pleno de determinada atividade, consideradas as possíveis limitações da deficiência.

O ponto em comum entre as duas leis é que propiciam a dois segmentos da população a condição diferenciada para inserção promovendo a igualdade de oportunidades.

\section{Empregadores}

O governo e demais órgãos e instituições dedicadas à promoção e proteção de direitos de ambos os segmentos seguem tentando mobilizar, alertar e punir empregadores; porém, uma grande parte das empresas ainda tenta se esquivar ou se defender do cumprimento da legislação.

A interpretação possível é que se todos aqueles que estão obrigados cumprissem a cota mínima de 5\% teríamos mais de um milhão de aprendizes.

É importante ressaltar que algumas grandes empresas já reconhecem e apresentam os bons frutos de investirem em programas corporativos, inclusive para efeitos de renovação de seus quadros com empregados que adquiriram valores internos da organização. Isso porque a empresa é responsável e partícipe da formação ofertada ao aprendiz. 
Quadro Comparativo de Aprendizes Admitidos em 2013

\begin{tabular}{|c|c|c|}
\hline UF & Potencial 5\% & $\%$ Cumprimento \\
\hline ES & 23.277 & 43,62 \\
\hline RS & 76.828 & 40,15 \\
\hline CE & 33.150 & 38,03 \\
\hline AM & 17.865 & 37,64 \\
\hline AP & 2.385 & 36,39 \\
\hline GO & 40.198 & 34,74 \\
\hline DF & 26.293 & 30,57 \\
\hline SE & 9.990 & 29,00 \\
\hline$A C$ & 2.748 & 28,13 \\
\hline SC & 54.595 & 28,07 \\
\hline MG & 128.062 & 27,95 \\
\hline SP & 379.367 & 26,90 \\
\hline TO & 7.293 & 26,48 \\
\hline PR & 73.570 & 25,93 \\
\hline RO & 10.515 & 25,37 \\
\hline BA & 57.902 & 24,94 \\
\hline RJ & 110.473 & 24,85 \\
\hline $\mathrm{AL}$ & 12.722 & 24,60 \\
\hline PE & 44.075 & 22,75 \\
\hline $\mathrm{RR}$ & 2.486 & 21,60 \\
\hline MT & 20.700 & 21,45 \\
\hline RN & 15.970 & 21,29 \\
\hline PA & 28.179 & 20,85 \\
\hline MS & 16.201 & 17,13 \\
\hline PB & 14.921 & 16,43 \\
\hline MA & 16.964 & 14,88 \\
\hline PI & 10.401 & 15,83 \\
\hline BRASIL & 1.237 .130 & 27,68 \\
\hline
\end{tabular}

Fonte: MTE - Potencial mínimo de cotas obrigatórias com base na Rais 2010. Contratação de aprendizes calculado pelas informações do Caged de jan. a dez./2013. 
Outros empregadores, quando inspecionados, apresentam argumentos verdadeiros na maioria dos casos - da ausência de entidades formadoras que atendam suas expectativas de qualificação de acordo com sua área de atividade. A esses, que em razão do porte da empresa já contribuem com os Serviços Nacionais de Aprendizagem - o conhecido Sistema S -, deveriam ser garantidas matrículas em quantidade suficiente, com variedade de cursos e programas e turmas abertas em vários meses do ano.

Infelizmente não é assim quando se trata de matrículas para o instituto da aprendizagem; o que deveria ser o principal objetivo desses entes cuja maior receita é oriunda da contribuição desses mesmos empregadores parece estar em segundo plano. Não que o Sistema $S$ não cumpra sua principal vocação da oferta de educação profissional e tecnológica no país; eles fazem e muito bem seu papel, mas para poucos e em muito poucos municípios, normalmente em cidades grandes. O que poderia ser resolvido com parcerias locais.

Retirado o foco em programas de aprendizagem pelo Sistema $S$, ainda que estejam ampliando a oferta de qualificação de trabalhadores em geral, obriga o empregador a procurar outra instituição formadora e financiar novamente as aulas teóricas, salvo se obtiver a matrícula em uma instituição pública federal ou estadual. O pior para todos, empresas, aprendizes e para o objetivo de desenvolvimento da localidade e do país, obrigado a contratar sua cota mínima, o empregador normalmente encontrará cursos na área administrativa - mais barato e com infraestrutura mais fácil - para que efetue a matrícula, requisito obrigatório nesse tipo de contrato.

Ao menos a empresa estará cumprindo com sua obrigação do ponto de vista social ao promover oportunidades de uma inserção decente, dirão muitos. De fato, que um adolescente tenha o acesso a esse tipo de contrato e possa se desenvolver competências técnicas e comportamentais inerentes ao trabalho em si, como a organização e o planejamento de atividades, atitudes e adquirir conhecimentos básicos e específicos de uma profissão na área administrativa que perpassa qualquer atividade econômica, é melhor do que não ter nenhuma oportunidade.

Felizmente, a recente e muito bem-vinda expansão das redes federal e estadual de educação profissional e tecnológica dos últimos anos parece que vai refletir na expansão dos números e na diversidade da oferta, e democratização do acesso. Já se vê crescer o interesse dessas instituições em fazer parcerias com grandes empresas para ofertar esse instituto que não parece ter concorrente, inclusive para combater a evasão escolar. Principalmente quando se trata de adolescentes em idade escolar, jovens cursando ou egressos do Ensino Médio ou ainda para atrair à modalidade de Educação de Jovens e Adultos (EJA), o enorme contingente que abandonou os estudos e encontra-se no máximo no mercado informal sem qualquer perspectiva de construir uma trajetória do ponto de vista pessoal e profissional, além da possibilidade de e inserção de pessoas com 
deficiência com necessidade de qualificação e/ou com defasagem escolar. Para esses pode ser ofertado um contrato de trabalho, com formação profissional de nível médio técnico.

\section{Exemplos para serem imitados}

\section{Aprendizes na administração pública diveta e autarquias federais}

Os órgãos da administração direta, que não estão obrigados a cumprir cotas, além de abrir voluntariamente oportunidades a cada dia, começam a despertar para a importância de motivar os prestadores de serviços a cumprir seu dever e assim melhorar a qualidade de seus serviços. $\mathrm{O}$ discurso desses prestadores de que a empresa/estabelecimento tomador de serviços não aceita o aprendiz no ambiente de trabalho não mais se sustenta com o início de programas corporativos pelos Tribunal Superior do Trabalho, Ministério Público do Trabalho, Previdência Social e Câmara dos Deputados que acolhem e participam da formação desses aprendizes.

\section{O Projeto cearense Aprendiz na Escola}

A Secretaria de Educação do Estado do Ceará, pioneiríssima na reestruturação do currículo de Ensino Médio tão necessária e vislumbrada desde a promulgação da Lei de Diretrizes e Bases da Educação (LDB) em 1996, inseriu a dimensão trabalho em duzentas horas-aulas ministradas a alunos matriculados no último ano do Ensino Médio regular.

Essa carga horária, vivenciada por todos os seus alunos, é reconhecida pelo Ministério do Trabalho e Emprego como a formação técnica geral, básica para qualquer novo trabalhador. A título de programas-piloto em doze escolas estaduais em 2014 (serão quarenta escolas em 2015), serão acrescidas mais duzentas horas distribuídas ao longo do ano no contraturno escolar, completando-se a formação profissional com a abordagem específica dos conteúdos relacionados a ocupações das áreas de tecnologia da informação, alimentação e administrativa. Concomitantemente, esses alunos, agora aprendizes, irão vivenciar atividades práticas nos estabelecimentos contratantes. Saem certificados e com experiência do primeiro emprego.

Outra modelo vem sendo ofertado pelas redes estaduais de ensino técnico de nível médio, quando os contratos podem iniciar desde o segundo ano desse nível, culminando com a diplomação técnica.

Esse fantástico exemplo dos programas-piloto do Ceará nos remete a uma reflexão sobre o propósito de se transformar todas as escolas de Ensino Fundamental para ensino integral. Os municípios, entes federados responsáveis por esse nível de ensino, podem resolver redesenhar seus currículos promovendo formas concretas de prevenir o trabalho infantil a partir do ambiente escolar. Seria uma das formas de dar fim à perversidade que é a informalidade e a exploração a que estão sujeitos os/as adolescentes que são submetidos ao trabalho em feiras, sinaleiros, manuseio agrícola e outras atividades ainda mais prejudiciais à saúde, ao direito ao lazer e, obviamente, ao futuro. 
Os empregadores certamente teriam interesse em contratar alunos das escolas e os alunos, em continuar na escola mesmo que precisem de renda, sabendo que aos quatorze anos podem acessar oportunidades como a de aprendizagem, que depois poderão ter acesso ao estágio em um curso técnico e superior até que se tornem profissionais plenos.

Com base no exposto, ainda que de forma breve, parece ser possível afirmar que a aprendizagem de fato é, e deve ser, mais bem explorada como a inserção ideal no mercado de trabalho, qualquer que seja o contexto social e econômico. Por reunir os binômios educação \& trabalho; renda \& proteção previdenciária e trabalhista, atividades teóricas \& práticas, torna-se efetiva e atrativa, despertando cada vez mais a atenção inclusive de organismos internacionais em razão de iniciativas louváveis que merecem ser conhecidas e replicadas.

O impacto do cumprimento desses dispositivos legais por empresas de todos os setores e atividades econômicas, públicas ou privadas, de qualquer porte, imprimirá celeridade e inclusão social ao processo de desenvolvimento social e econômico do Brasil.

\section{Nota}

1 Documento elaborado pelo Subcomitê instituído por força do Decreto Presidencial de 4 de junho de 2009, que também criou um Comitê Executivo Interministerial responsável pela implementação da Agenda Nacional do Trabalho Decente de 2006, disponível em <http://portal.mte.gov.br>.

RESUMO - O Ministério do Trabalho e Emprego é o responsável pela fiscalização do cumprimento das Leis n.8.213/91 e n.10.097/2000 que dispõem, respectivamente, sobre cotas obrigatórias para garantir que empresas mantenham em seus quadros de empregados um percentual de pessoas com deficiência e, independentemente, acrescentem ao seus efetivos o número mínimo equivalente a $5 \%$ de adolescentes e jovens por intermédio dos contratos especiais de trabalho. Como aprendizes, no período de até dois anos que pode durar o programa de formação técnico-profissional metódica, irão desenvolver a teoria e prática relacionada a uma ou mais ocupações referente à atividade econômica desenvolvida pelo empregador. Concebida para qualificar e proteger o processo de inserção do jovem trabalhador, a lei do aprendiz pode aumentar em muito a efetividade da Lei n.8.213, quando isso se aplicar.

PALAVRAS-CHAVE: Trabalho decente, Formação profissional, Inserção, Mercado de trabalho.

ABSTRACT - The ministry of Labor is responsible for enforcement of Act n. 8.213/91 and n.10.097/2000 which have respectively on mandatory quotas to ensure that companies maintain on its staff of employees a percentage of people with disabilities and independently add to its effective equivalent to $5 \%$ of young people through the special work contracts minimum. As apprentices, in the period up to two years can last program 
methodical technical and vocational training, will develop the theory and practice related to one or more occupations related to economic activity developed by the employer. Designed to qualify and secure the process of insertion of the young worker, the law of the learner can greatly increase the effectiveness of the Law n.8213, when it applies. KErWORDS: Decent work, Vocational training, Insertion, Labour market.

Ana Lucia de Alencastro Gonçalves é coordenadora geral de Preparação e Intermediação da Mão de Obra Juvenil (CGPI) do Ministério do Trabalho e Emprego, Brasília (DF). @- anaalencastromte@gmail.com

Recebido em 30.6.2014 e aceito em 7.7.2014.

${ }^{\text {I } M i n i s t e ́ r i o ~ d o ~ T r a b a l h o ~ e ~ E m p r e g o, ~ B r a s i ́ l i a / D F, ~ B r a s i l . ~}$ 